\title{
Redes sociais e eleições municipais: um estudo sobre a campanha no Facebook do candidato Assis Ramos em Imperatriz-MA ${ }^{1}$
}

\author{
Social networks and municipal elections: a study on the Facebook campaign \\ of the Assis Ramos candidate in Imperatriz-MA
}

\section{Redes sociales y elecciones municipales: um estudio sobre la campaña en Facebook del candidato Assis Ramos en Imperatriz-MA}

\author{
Vitor Curvelo Fontes Belém ${ }^{2}$ \\ Carla Costa Farias ${ }^{3}$ \\ Rebeca Andrade Avelar ${ }^{4}$
}

\begin{abstract}
Resumo
A inserção das redes sociais no cotidiano tornou-se uma arena de discussões, (des)construção e campo de (in)formação. É nesse contexto que se insere a proposta deste trabalho, que busca analisar o uso do Facebook como estratégia de projeção, tendo como corpus as publicações da fanpage oficial do candidato Assis Ramos (PMDB) à prefeitura da cidade de Imperatriz - MA. Desta maneira, busca-se compreender como essa ferramenta colaborou com a construção da imagem do político, promovendo o engajamento do público nas redes sociais durante a campanha eleitoral, no período de 16 de agosto a 01 de outubro de 2016. Para dar sustentação à pesquisa inicial, se fez necessário revisar os conceitos de propagação e engajamento (JENKINS; FORD; GREEN, 2014) e como procedimento metodológico, optou-se pelo estudo de caso (YIN, 2015). O estudo aponta que nesse contexto local as redes sociais impulsionam a popularidade do candidato aumentasse e auxiliam no planejamento de estratégias de comunicação para outras mídias.
\end{abstract}

Palavras-Chave: Redes Sociais. Facebook. Campanha Eleitoral. Engajamento.

\begin{abstract}
The insertion of social networks in everyday life has become an arena of discussion, (de) construction and field of (in) formation. It is in this context that the proposal of this work, which seeks to analyze the use of Facebook as a projection strategy, is inserted, having as corpus the publications of the official fanpage of the candidate Assis Ramos (PMDB) to the prefecture of the city of Imperatriz MA. In this way, it is sought to understand how this tool collaborated with the construction of the image of the politician, promoting the public engagement in social networks during the electoral campaign, from August 16 to October 1, 2016. To support the research it was necessary to review the concepts of propagation and engagement (JENKINS; FORD; GREEN, 2014) and as a methodological procedure, the case study (YIN, 2015) was chosen. The study points out that in this local context
\end{abstract}

\footnotetext{
${ }^{1}$ Versão desse trabalho foi apresentada no $15^{\circ}$ Encontro Nacional de Pesquisadores em Jornalismo SBPJor, realizado na ECA-USP, em novembro de 2017.

2 Jornalista, com especialização em Comunicação Empresarial e Institucional pela UFMA e MBA em Marketing pela INESPO. Integrante do Grupo de Pesquisa em Convergência e Narrativas Audiovisuais (CONNAU). Email: kassiscarla@gmail.com.

${ }^{3}$ Professor da Pós-Graduação (Mestrado) e do Departamento de Jornalismo da Universidade Estadual de Ponta Grossa (UEPG). Pós-doutor em Jornalismo pela UEPG. Doutor em Sociologia Política pela Universidade Federal de Santa Catarina (UFSC). Mestre em Jornalismo pela UFSC. Graduado em Jornalismo pela Universidade Estadual de Ponta Grossa (UEPG). E-mail: felipe271184@yahoo.com.br.

${ }^{4}$ Jornalista (UFMA). Integrante do Grupo de Pesquisa em Convergência e Narrativas Audiovisuais (CONNAU). E-mail: rebecaandrade.avelar@hotmail.com.
}

Comun. \& Inf., Goiânia, GO, v. 21, n. 1, p. 126-141, jan./mai. 2018 
social networks drive the popularity of the candidate to increase and help in the planning of communication strategies for other media.

Keywords: Social networks. Facebook. Election campaign. Engagement.

Resumen

La inserción de las redes social es en el cotidiano se ha convertido en una arena de discusiones, (des) construcción y campo de (in) formación. En este contexto se inserta la propuesta de este trabajo, que busca analizar el uso de Facebook como estrategia de proyección, teniendo como corpus las publicaciones de la fanpage oficial del candidato Asís Ramos (PMDB) al ayuntamiento de laciudad de Emperatriz - MA. De esta manera, se busca compreender como esa herramienta colaboró com la construcción de la imagen del político, promovendo el compromisso del público em las redes sociales durante la campaña electoral, em el período del 16 de agosto al 1 de octubre de 2016. Para dar sustentación a la investigación (por ejemplo, en el caso de las mujeres). El estúdio apunta que en ese contexto local las redes sociales impulsan la popularidade del candidato aumentan y auxilian en la planificación de estrategias de comunicación para otros medios.

Palabras clave: Redes sociales. Facebook. Campaña electoral. Compromiso.

\section{INTRODUÇÃO}

inserção das redes sociais no cotidiano tornou-se uma arena de discussões,
(des) construção e campo de (in) formação. É nesse contexto que se insere
a proposta deste trabalho, que busca analisar o uso da mídia social como
estratégia de projeção, tendo como corpus a página no Facebook do candidato à prefeitura da cidade de Imperatriz - MA, Assis Ramos construção da imagem do político, promovendo um engajamento do público nas redes sociais durante a campanha eleitoral, no período de 16 de agosto de a 01 de outubro de 2016. Para dar sustentação à pesquisa inicial, se fez necessário uma pesquisa bibliográfica, para revisão dos principais conceitos que envolvem o estudo, um levantamento de informações na base de dados do Tribunal Superior Eleitoral (TSE), Tribunal Regional Eleitoral (TRE), além de matérias publicadas na imprensa local. Como estratégia metodológica, optou-se pelo estudo de caso (YIN, 2015) e a análise de conteúdo, para observação e análise do corpus composto pelas publicações na fanpage do candidato durante o período eleitoral. A partir do recorte feito na plataforma, algumas variáveis que mais impactaram as divulgações na rede foram levantadas para análise durante a pesquisa.

Foram realizadas entrevistas abertas com os atores responsáveis pela criação, estratégia e publicação do material durante o período de pré e campanha do candidato analisado, com o objetivo de levantar o máximo de informações sobre a movimentação da 
equipe nas redes sociais, quais ferramentas utilizaram e como esse formato de ações poderia impactar a imagem do então candidato nas redes. A partir dos estudos através de alguns autores sobre o campo das redes sociais, sobretudo analisando esse processo de convergência, que no entendimento de Jenkins (2006) é mais amplo do que um processo tecnológico, possibilita não só o acesso ao desenvolvimento e ao uso de novas tecnologias, mas a própria relação da comunicação entre as empresas e o seu público em questão, de maneira que o conteúdo dá oportunidade de transformação e propagação pelo consumidor.

É a partir deste conceito, tendo em vista as publicações da página do candidato Assis Ramos no Facebook realizadas no período eleitoral, que se concentra a análise deste trabalho. $\mathrm{Na}$ intenção de compreender os aspectos que colaboraram para a construção da imagem política do candidato Assis Ramos, investigou-se empiricamente os fatos da campanha online, acompanhados das evidências quantitativas a respeito das publicações na fanpage oficial e entrevistas com a equipe de comunicação do candidato.

Portanto, nos próximos tópicos serão abordadas de forma ampla as estratégias que orientaram a edificação do perfil político do candidato à Prefeitura de Imperatriz- MA, apresentando pesquisas recentes que discutem a inserção das redes sociais como ferramentas de comunicação eleitoral.

\section{INTERNET, REDES SOCIAIS E ELEIÇÕES}

As novas mídias ampliaram as possibilidades de comunicação e relacionamento no contexto das campanhas eleitorais. Por meio do surgimento dos sites de redes sociais, bem como dos mecanismos interacionais que estes possuem, o diálogo entre candidatos e eleitores adquiriu nuances diferenciadas. Os recursos digitais permitiram armazenar maior volume de informações acerca das candidaturas, associados à disseminação rápida e personalizada destes conteúdos.

Outra questão a ser considerada, segundo Stromer-Galley (2000), é o caráter participativo que o cidadão assume em meio às decisões políticas, desde o período da disputa eleitoral. As formas de engajamento online possíveis na relação representantes-representados mediada pelas redes sociais digitais incitam o engajamento cívico.

Convém, portanto, mencionar que a prática da utilização das redes sociais em disputas eleitorais se popularizou a partir do fenômeno Obama, em 2008. A bem-sucedida campanha online do ex-presidente estadunidense evidenciou um panorama de transformações, no qual a 
inserção das redes sociais potencializou as estratégias de comunicação eleitoral e política. (GOMES et al., 2011; AGGIO; MARQUES; SAMPAIO, 2012). O nível de mobilização observado na campanha de Obama gerado pelo uso coordenado de redes sociais e aplicativos móveis gerou um ambiente de aproximação com o eleitorado.

Tendo em vista as eleições municipais no ano de 2016, compreende-se que as alterações na regra das campanhas, decorrentes Lei no 13.165/2015, também conhecida como Reforma Eleitoral 2015, impulsionaram o uso de mídias sociais enquanto ferramentas de comunicação eleitoral de uma forma inédita no Brasil.

De acordo com o Tribunal Superior Eleitoral (TSE), as principais mudanças que fomentaram a utilização das redes sociais foram: A proibição da doação de campanhas por empresas, sendo permitida apenas doações de pessoas físicas e financiamento com recursos do Fundo Partidário; A duração das campanhas, que foram reduzidas de 90 para 45 dias, iniciando em 16 de agosto, finalizando no 02 de outubro (colégios eleitorais com até 200 mil eleitores); A possibilidade de campanha antecipada, por meio das redes sociais e participações de eventos públicos, desde que não houvesse pedido explícito de voto; Encurtamento da propaganda eleitoral gratuita no rádio e TV, com 35 dias de exibição, 10 a menos que nas disputas anteriores, sendo que o formato permitido foi reduzido para dois blocos de 10 minutos e não mais de 30 minutos; E a proibição de exposição de cavaletes nas ruas e calçadas com propagandas de partidos ou candidatos.

Ponderando o cenário eleitoral mencionado, infere-se que as redes sociais protagonizaram uma parte das estratégias de comunicação dos candidatos rumo ao êxito nas urnas, sobretudo, no contexto da candidatura de Assis Ramos à prefeitura de Imperatriz. Dentre as alternativas que as redes sociais na internet oferecem na disputa eleitoral, ressalta-se a perspectiva de identificação do candidato com o seu eleitorado.

Um dos pontos-chaves atrelados ao fator aproximação na relação candidato-eleitoré o conceito de reputação, estudado por Recuero (2009). A reputação é um dos valores construídos nas mídias sociais, a partir da publicidade de informações e do consumo deste conteúdo quantificado pelas interações disponíveis em cada plataforma. $\mathrm{O}$ discurso de um político cunhado ao longo de uma campanha eleitoral nas redes sociais é capaz de modificar e ampliar a percepção dele junto ao seu público-alvo, que, por conseguinte, influencia no nível de visibilidade que este candidato tende a conquistar durante o processo da disputa eleitoral.

\section{FACEBOOK COMO ESTRATÉGIA DE COMUNICAÇÃO ELEITORAL}

Comun. \& Inf., Goiânia, GO, v. 21, n. 1, p. 126-141, jan./mai. 2018 
Estar inserido no ambiente digital permite um fluxo entre emissor e receptor cada vez mais próximo, com aberturas imediatas para novas construções da informação, que são repassadas através das plataformas. Com canais cada vez mais interligados com o público, as marcas, serviços, pessoas ou produtos que emitem uma determinada informação, precisam agora entender como o processo se desenvolve nesse ambiente virtual, e de como a informação ganha novas dimensões, com as múltiplas interpretações feitas pelos usuários na rede.

O crescimento da comunicação em rede, especialmente quando associada às práticas de cultura participativa, cria uma diversidade de novos recursos e facilita novas intervenções para uma variedade de grupos que há muito tempo lutam para se fazer ouvir. Novas plataformas criam aberturas para mudanças sociais, culturais, econômicas, legais e políticas, além de constituírem oportunidades para a diversidade e a democratização, pelas quais vale a pena lutar (JENKINS; FORD; GREEN, 2014, p. 20-22).

É dentro desta perspectiva apontada, que entendemos que a participação cada vez mais ativa do público nos permite enxergar uma construção social diferenciada dentro do espaço virtual. Nesse campo, a mobilização em torno de algo e a oportunidade de verbalizar e se engajar em uma causa é muito maior e mais rápida, quando relacionamos ao processo de comunicação nas mídias tradicionais. Desta forma, se faz necessária a compreensão desta nova dimensão comunicacional inserida no contexto das campanhas eleitorais. A crescente presença de agentes políticos, partidos, movimentos sociais e empresas jornalística nas redes sociais digitais como Facebook, Twitter e YouTube (PARMELEE; BICHARD, 2012) constatam um momento diferenciado, no que diz respeito a comunicação eleitoral em ambientes online.

Considerando os motivos que apontam a importância da análise do social media em campanhas online, Aggio (2013) destaca a vantagem numérica de usuários que os sites deredes sociais possuem e a forma de organização social que estas plataformas permitem ao criar conexões entre grupos de características geográficas, ideológicas, políticas e sociais diversas na disseminação de conteúdo. A partir do momento em que cada grupo se conecta em rede, uma nova organização de conteúdo e de proliferação de ideias e discursos passa a fazer parte de um determinado assunto, engajando assim a participação junto as essas informações de uma forma cada mais intensa pelos usuários.

Ao considerar o uso do Facebook como instrumento de comunicação eleitoral, as pesquisas no Brasil ganham força nas eleições de 2012, período que se constatou também um 
recorde de crescimento de usuários na rede no Brasil. Em junho de 2012, o país alcançou 54 milhões de usuários, representando 5,6\% do total de usuários da rede social em todo o mundo, de acordo com a Securitiesand Exchange Commission, órgão regulador americano.

Bachini(2012) pontua que o uso do Facebook em pleitos anteriores, se restringiu à função de divulgação de ações e agenda dos candidatos, não explorando a rede social sob um viés aprofundado no que tange ao relacionamento e interação com o usuário, ou seja, o eleitor. Deste modo, no presente estudo, a intenção é precisamente analisar as formas de apropriação do Facebook na campanha política do candidato Assis Ramos. É válido frisar ainda, que este recorte local segue a lógica de uso prevista por Carlomagno (2015). O autor enfatiza que o Facebook e Twitter são as plataformas preferidas dos candidatos desde as eleições 2012, devido ao baixo custo financeiro e o fácil acesso.

Contudo, para Penteado (2011), o espírito da web 2.0 não foi incorporado às estratégias de utilização desta rede social, expondo, portanto, a fragilidade comunicacional das campanhas em se apropriarem da plataforma, haja visto todo o seu potencial dialógico. Esta afirmação, pôde ser inclusive, observada neste estudo, onde foi possível notar repetições nos temas das postagens, a forma convencional na questão dos formatos utilizados nas publicações, e uma amostra reduzida de interações diretas dos usuários, via comentários nos posts.

A seguir, pretende-se desenvolver os conceitos de engajamento e propagação, temas basilares no que diz respeito à compreensão do nível de interatividade nas redes sociais medido e observado por pesquisas anteriores em campanhas eleitorais online.

\subsection{ENGAJAMENTO E PROPAGAÇÃO}

Dentro de um cenário na web com multiplataformas, existe então um campo aberto para duas questões fundamentais dentro das redes sociais: o engajamento e a propagação. Levando-se em consideração que o público está cada vez mais disposto a procurar conteúdo em diversos canais, "os modelos baseados em engajamento veem a audiência como uma cooperativa de agentes ativos cujo trabalho pode gerar formas alternativas de valor de mercado" (JENKINS; FORD; GREEN, 2014, p.153).

No Facebook, por exemplo, os indicadores de curtidas já apontam a quantidade de usuários envolvidos em torno de uma informação, mas isso ainda não é o suficiente para que tal conteúdo ganhe força e circule com mais velocidade na internet. A audiência engajada na 
rede social vai, além disso, recomendando, discutindo, repassando ou mesmo criando novos conteúdos a partir das informações.

Nesse sentido, Marques e Sampaio (2011) avaliam a importância dos mecanismos de interação do Facebook como o 'input' inicial para a distribuição do conteúdo em rede, a começar pelos próprios perfis conectados direto ao usuário. O "curtir", "compartilhar" e "comentar" ativam o engajamento e o espalhamento da informação relevante.

Sendo assim, diante deste contexto comunicacional, cabem alguns questionamentos. Como construir um conteúdo para que a audiência esteja envolvida? Como podem ser traçados o caminho vitorioso para uma campanha política? Investir no mapeamento dessas informações pode ser fundamental para o sucesso. Ou seja, investir em conhecer o modelo de conteúdo e a forma como os indivíduos desejam interagir nas plataformas, faz com que cada empresa desenvolva ferramentas para aproximação e a identificação desse público multiplicador de conteúdos ou conceitos.

Com o amplo uso da Internet e o crescimento do Google, a sociedade passou a ser dona do amplo conhecimento: todos podem conhecer tudo. A informação passou a ser posse de todos, todos podem a qualquer momento pesquisar e conhecer sobre tudo e sobre todos. A proliferação da informação transformou esta em mercadoria e, com o tempo, entendeu-se que as próprias pessoas passaram a ser informação e, consequentemente, se tornaram mercadorias. (BRUGNAGO; CHAIA, 2014, p. 119).

Na prática, esse é um dos passos para pensar a propagabilidade na disseminação de conteúdos pelo público. O fato é que esse processo esbarra no modelo de relações antigas entre os meios de comunicação e a sociedade, que se estabelecia pelo fluxo informacional em único sentido. É, portanto, um desafio.

Essa tarefa implica o desenvolvimento de um ativismo capaz de intervir na televisão de acesso público, na rádio comunitária, nos meios de comunicação por computador e em outros domínios que hoje estão surgindo. Para obterem uma participação genuína, as pessoas precisam adquirir conhecimentos sobre a produção da mídia e sobre a criação de produtos divulgáveis. A intensificação do ativismo na mídia poderia ampliar significativamente a democracia, com a proliferação de novas idéias e com a possibilidade de manifestação das opiniões até agora silenciadas ou marginalizadas (KELLNER, 2001, p. 426).

As opiniões citadas por Kellner (2001) também ganham força em todo e qualquer conteúdo que desperte o interesse do usuário na rede. Na política, a proliferação de ideias e o fácil acesso da informação na internet, gera um envolvimento do público, não só para 
manifestação de apoio, mas fortalece e dissemina cada vez mais com a interação feita pelo usuário na rede. O público está próximo do candidato e acaba fazendo parte do processo de divulgação da campanha de forma indireta e direta, envolvendo outros usuários na web.

Reiterando os estudos sobre o fluxo de informações nas redes sociais com vistas à comunicação eleitoral, cita-se Towner e Dúlio (2013). Os autores destacam que o Facebooké o site de rede social mais bem sucedido na área da comunicação político-eleitoral, uma vez que a plataforma permite conectar eleitores, reforçando os desejos políticos de mobilização online e offlline. Além disso, possibilita a interligação com outras mídias sociais como o Twitter, YouTube, e mais recentemente o Instagram.

Somada a esta afirmação, registra-se também um grande volume de acesso da rede no Brasil. São 83\% dos brasileiros estão ativos no Facebook, segundo a Pesquisa Brasileira de Mídia (BRASIL, 2014). E ao observar o cenário regional de utilização da mídia social, encontra-se de 1,5 à 2 milhões de usuários no Estado do Maranhão, e no munícipio de Imperatriz são 150 a 200 mil perfis ativos mensalmente, de acordo com os dados coletados e disponibilizados no Facebook.

\section{CAMPANHA POLÍTICA NO FACEBOOK: O CASO DO CANDIDATO ASSIS RAMOS EM IMPERATRIZ}

Durante 45 dias o Facebook tornou-se uma das ferramentas com grande poder de alcance para as campanhas políticas. Os dados apontam mais de 1,39 bilhão ${ }^{5}$ de usuários ativos por segundo, trocando mensagens, levando uma visão partidária para fora das paredes, atraindo novos militantes e aumentando a base de fãs, seja de que conteúdo o usuário esteja relacionado.

Observando o panorama das eleições 2016 em Imperatriz-MA, quatro dos seis candidatos a prefeito (a) utilizaram o Facebook de forma profissional por meio de fanpages oficiais. Os candidatos Ildon Marques (PSB), Rosângela Curado (PDT) e Ribinha Cunha (PSC) mantiveram uma rotina de publicações durante todo o período eleitoral no Facebook. Este fato acompanha a tendência pelo favoritismo que rede social tem conquistado como estratégia de comunicação político-eleitoral, já mencionada na revisão da literatura.

\footnotetext{
5 Informação da matéria divulgada no Grupo e Mídia: <http://www.grupoemidia.com/blog/marketingpolitico/quais-as-regras-para-campanha-eleitoral-na-internet-em-2016> Acesso em: 29 nov. 2016.
} 
Deste modo, entende-se que o Facebook se configurou como uma das estratégias centrais da campanha online de Assis Ramos (PMDB), tendo como objetivo o processo de construção da imagem política do candidato ao longo do período eleitoral.

A fim de compreender o contexto no qual se insere esta análise, faz-se necessário pontuar algumas questões. A primordial delas é fato de que Assis Ramos registrou-se pela primeira vez, em 2016, para concorrer a um cargo político, o de prefeito. A informação consta no banco de dados do Tribunal Superior Eleitoral (TSE). Até este momento, a imagem dele na região era vinculada apenas ao cargo de delegado de Polícia Civil; uma figura pública, mas sem vínculo com a política. Durante o pleito, o delegado era um dos seis candidatos disputando o cargo. A maioria dos concorrentes teve trajetória na política local, com candidaturas anteriores e, até mesmo, mandatos cumpridos. Nesse cenário, uma pesquisa realizada pela Escutec $^{6}$, em julho de 2016, apontava uma eleição imprevisível na cidade de Imperatriz, com porcentagem equilibrada entre os quatro primeiros colocados. $\mathrm{O}$ candidato Assis Ramos aparecia em terceiro lugar, com 22,6\% das intenções de voto, e com uma possível tendência de crescimento, segundo a pesquisa. Em setembro de 2016, o Instituto Gauss $^{7}$ divulgava outra pesquisa, que indicava uma eleição polarizada e, novamente, com o candidato Assis Ramos com 21,49\% das intenções, reforçando o terceiro lugar nas pesquisas.

As pesquisas associadas ao fato de que o candidato estava iniciando sua trajetória política, foram decisivas na preparação de uma estratégia de comunicação eleitoral que incluísse a utilização das redes sociais como ferramenta de diálogo com o eleitor. A tática definida pela coordenação da campanha consistiu em reforçar a imagem política para além das mídias tradicionais. Somadas às visitas nas comunidades e às inserções partidárias em TV e rádio, a equipe de assessoria criou grupos no Whatsappe perfis nas redes sociais, para ampliar a divulgação da agenda e das propostas da coligação, buscando conquistar visibilidade e engajamento do público nas redes sociais.

Figura 1 - Interface da página inicial da fanpage“Assis Ramos”

\footnotetext{
${ }^{6}$ Filiada à ABEP- Associação Brasileira de Empresas de Pesquisa, a Escutec foi fundada em 1994 e realiza pesquisas de mercado e de opinião pública. Pesquisa disponível em: <http://www.escutec.com/pesquisas.php?codigo1=152>. Acesso em: 29 nov. 2016.

${ }^{7}$ A Gauss Estatística\& Mercado atua há 15 anos no desenvolvimento de pesquisas de mercado. Pesquisa disponível em: <http://www.gaussem.com.br/index.html>. Acesso em: 29 nov. 2016.
}

Comun. \& Inf., Goiânia, GO, v. 21, n. 1, p. 126-141, jan./mai. 2018 


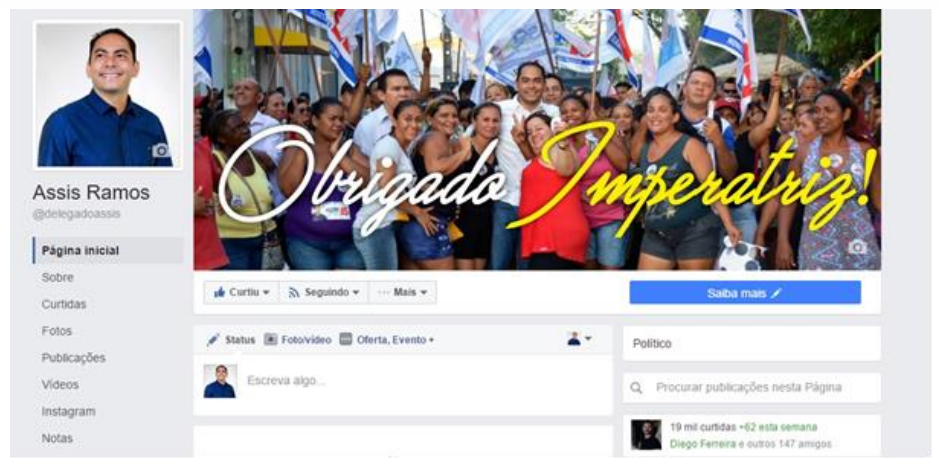

Fonte: Recorte da página do candidato no Facebook (2016)

A equipe de comunicação formatou o perfil do delegado no Facebook, alinhando os conteúdos com a fanpage (Figura 1), e na tentativa de expandir as informações, criou-se também um grupo público na rede social para divulgar as ações da campanha. Apesar dos três espaços, inseridos na web, era a fanpage o canal oficial para dialogar com o eleitorado online e minimizar os efeitos de boatos e notícias negativas no decorrer da disputa eleitoral e com grande disseminação principalmente na web. Além do uso do Facebook, a equipe mantinha um perfil comercial no Instagram do candidato e o website, criado especificamente para utilização no período da campanha.

Apesar da campanha de Assis Ramos ter um monitoramento das notícias veiculadas com o nome do candidato na $\mathrm{TV}$, no rádio, no impresso e na internet, era nas redes sociais que a equipe conseguia mensurar a participação e o envolvimento do público com as propostas e o modelo de governo do candidato, a partir de cada publicação feita.

É o que Jenkins, Ford e Green (2014) apontam como desafio para medição nas mídias tradicionais; e foi somente a partir da rede social que foi possível valorizar o engajamento do público no espaço virtual, permitindo que informações importantes tivessem maior fluidez, chegando ao conhecimento do público de forma quase instantânea. Além de valorizar o potencial multiplicador, a estratégia de mídia online tornou-se uma fonte oficial para a imprensa.

\section{ANÁLISE DOS DADOS}

Ao longo dos 47 dias de campanha eleitoral nas redes sociais, a saber, do dia 16 de agosto a 01 de outubro, foram realizadas 409 publicações na fanpage de Assis Ramos. Não foi incluso na análise o dia 02 de outubro, uma vez que o candidato venceu o pleito eleitoral, e 
as publicações realizadas neste dia alcançaram níveis de engajamento elevados. Estas publicações não se enquadraram na perspectiva de campanha eleitoral.

A fim de compreender a estratégia de conteúdos priorizada pela equipe da campanha online na página, e de como esse conjunto de informações ativou o engajamento online e offline, verificou-se o volume de interações dentro do período estudado e por publicação, a média de publicações ao dia, os formatos utilizados, bem como os temas que ganharam destaque.

No que se refere os três mecanismos prioritários de interação do Faceboook (Gráfico 1), foi contabilizada 10.909 reações (curtir, amei, haha, uau, triste e grr), representando $76 \%$ das interações, 3.137 comentários, denotando 6\% das interações, e 10.052 compartilhamentos equivalente a 18\% das ações dos usuários na página, conforme o gráfico abaixo.

Gráfico 1 - Seleção de interações na página do candidato

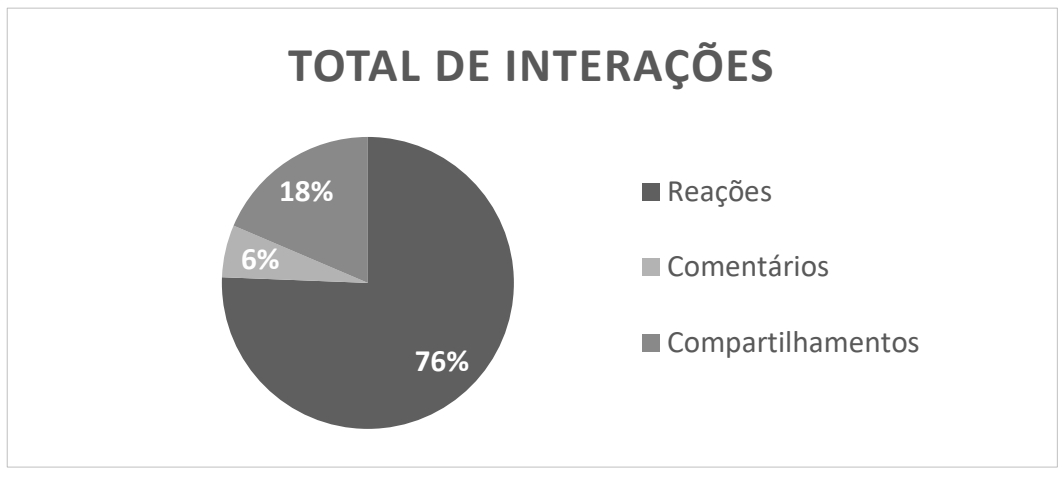

Fonte: Connau/UFMA/CNPq

O panorama geral das interações obtidas durante o período eleitoral na página do candidato, indica que os temas versados nos conteúdos publicados foram relevantes ao público, uma vez que despertou o interesse do mesmo, em interagir por meio dos recursos que a plataforma Facebook disponibiliza: "curtir", "compartilhar" e "comentar". Porém, é possível inferir que este nível de interatividade se manteve superficial, não conduzindo o eleitor a avançar na sua relação com o tema publicado através de um comentário, ou ainda compartilhando esta informação com a sua própria rede de contatos.

Podemos, no entanto, atribuir a frequência de publicações como um ponto positivo na construção deste volume de interações observadas na página. Verificou-se que durante os 47 dias de campanha online, foram postados conteúdos diários, atingindo uma média de 8,7 publicações ao dia.

O gráfico 2 a ser analisado a seguir, consiste na visão geral acerca dos formatos escolhidos para as publicações. Este item pode ser compreendido como o reflexo da 
versatilidade na produção de materiais informativos que consigam gerar o interesse do usuário, devido às possibilidades gráficas e audiovisuais que as redes sociais proporcionam.

Gráfico 2 -Gráfico sobre o formato das publicações na página

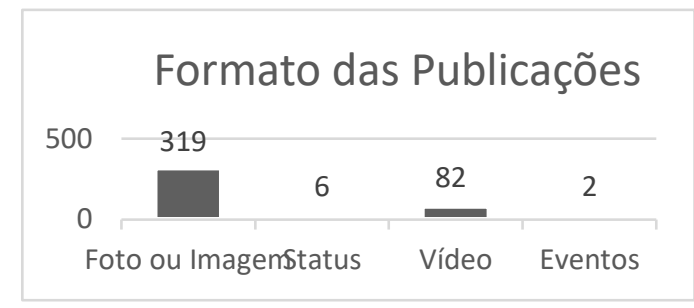

Fonte: Connau/UFMA/CNPq

Constatou-se que $78 \%$ das publicações foram fotos ou imagens, sendo o formato utilizado frequentemente nas publicações, representando 319 publicações. Postagens em vídeos ocupam o segundo formato mais utilizado, sendo escolhido para $20 \%$ das publicações. E com 1\% cada, os formatos de status e evento, formas próprias do Facebook.

De acordo com equipe de comunicação da campanha, a prevalência das fotos/imagens deve-se ao objetivo de enfatizar a divulgação da agenda do candidato, bem como, detalhar as ações de ruas. Vale destacar, que houve um fotógrafo para a cobertura de todo o período eleitoral. Se tratando dos vídeos, esta forma de comunicação, deve-se principalmente à reprodução dos programas eleitorais no Facebook, via publicação direto no feed de notícias e compartilhamento do link do canal do YouTube de Assis Ramos. Houve ainda a produção de vídeos curtos e vídeos amadores pelo próprio candidato. Entretanto, a live ${ }^{8}$, onde é possível disponibilizar o vídeo na linha do tempo após o término da transmissão, foi utilizado apenas 02 duas vezes. E ao considerar outros formatos, como por exemplo, o giff e o compartilhamento de link externo, não existiu nenhuma postagem.

Investigando a linha de planejamento de conteúdo da página junto aos analistas de social media da campanha, distinguiu-se 07 grupos temáticos que nortearam a produção dos posts. Esses grupos são: Agenda do Candidato e Informações; Defesa de ataques dos concorrentes, Discurso de vitória e propostas; Uso de Memes; Reprodução de programas eleitorais e inserções; Matérias do candidato na imprensa local; E assuntos pessoais, que incluíam posts sobre datas comemorativas e registro de atividades não ligadas à política. A fanpage abordou, em linhas gerais, o mesmo conteúdo desenvolvido pela equipe de campanha para as mídias tradicionais (TV, impresso e rádio), mas privilegiando a linguagem e o formato adaptado para as redes sociais conforme os recursos interativos disponíveis na web. As

\footnotetext{
${ }^{8}$ Ferramenta pode ser utilizada para fazer vídeos ao vivo dentro da plataforma do Facebook.
}

Comun. \& Inf., Goiânia, GO, v. 21, n. 1, p. 126-141, jan./mai. 2018 
perguntas in box, os comentários com dúvidas e agradecimentos em primeira pessoa, permitiu uma aproximação com o público, fato que contribuiu para ampliar a percepção do eleitor em meio ao processo de (re) definição da imagem do candidato.

Concernente às publicações que se destacaram dentro do recorte escolhido, explorouse 03 variáveis, a publicação com mais reações, mais compartilhamentos e mais comentários, com o objetivo de relacionar os conceitos de engajamento e propagação, discutidos anteriormente. A postagem (Quadro 1) que obteve mais comentários foi publicada no dia anterior à eleição.

Quadro 1 - Descrição de interação da publicação em vídeo publicada na página

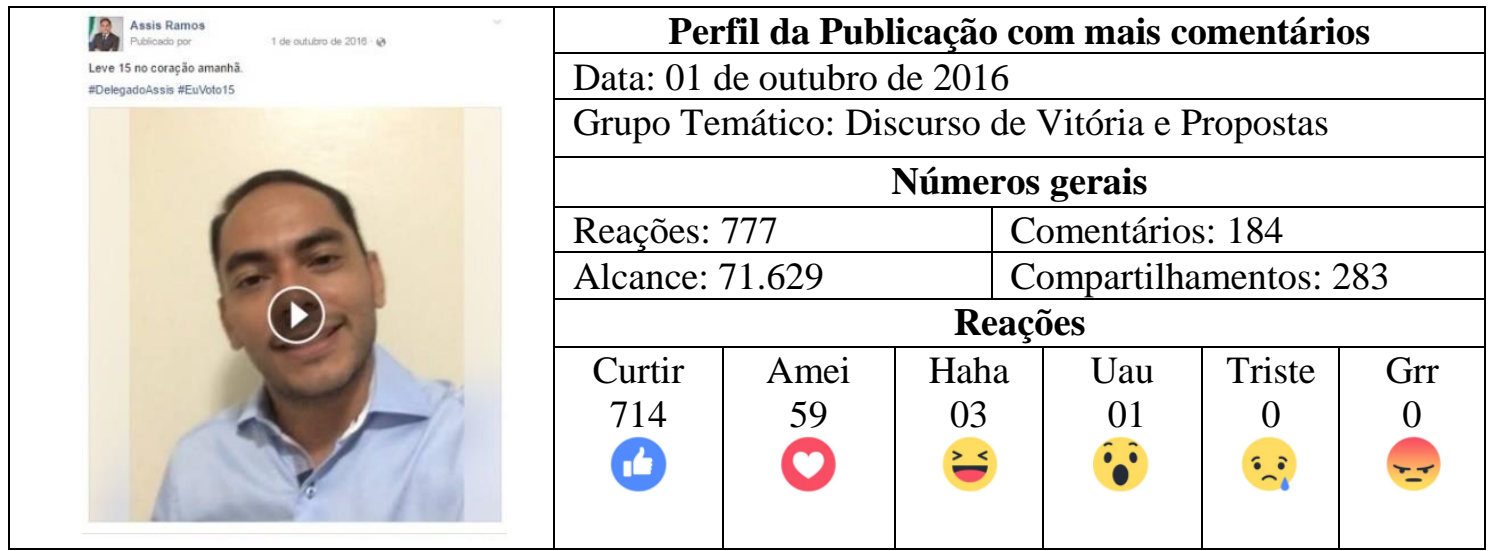

Fonte: Recorte da página do candidato no Facebook (2016) eConnau/UFMA/CNPq

O conteúdo (Quadro 1) consiste em um vídeo feito pelo próprio candidato, onde a mensagem clara de pedido de voto, em tom emocional, incentivou a manifestação do eleitor, gerando assim, 184 comentários, alcançando organicamente mais de 70 mil perfis ativos do Facebook. Vale dizer que formato audiovisual tem ganhado visibilidade no Facebook, funcionando como uma estratégia viável para envolver o usuário.

A publicação que se registrou a maior quantidade de reações foi a postagem realizada em tempo real (Quadro 2), momentos antes do primeiro debate televisionado da campanha. 
Quadro 2 - Descrição da publicação feita em tempo real e publicada na página

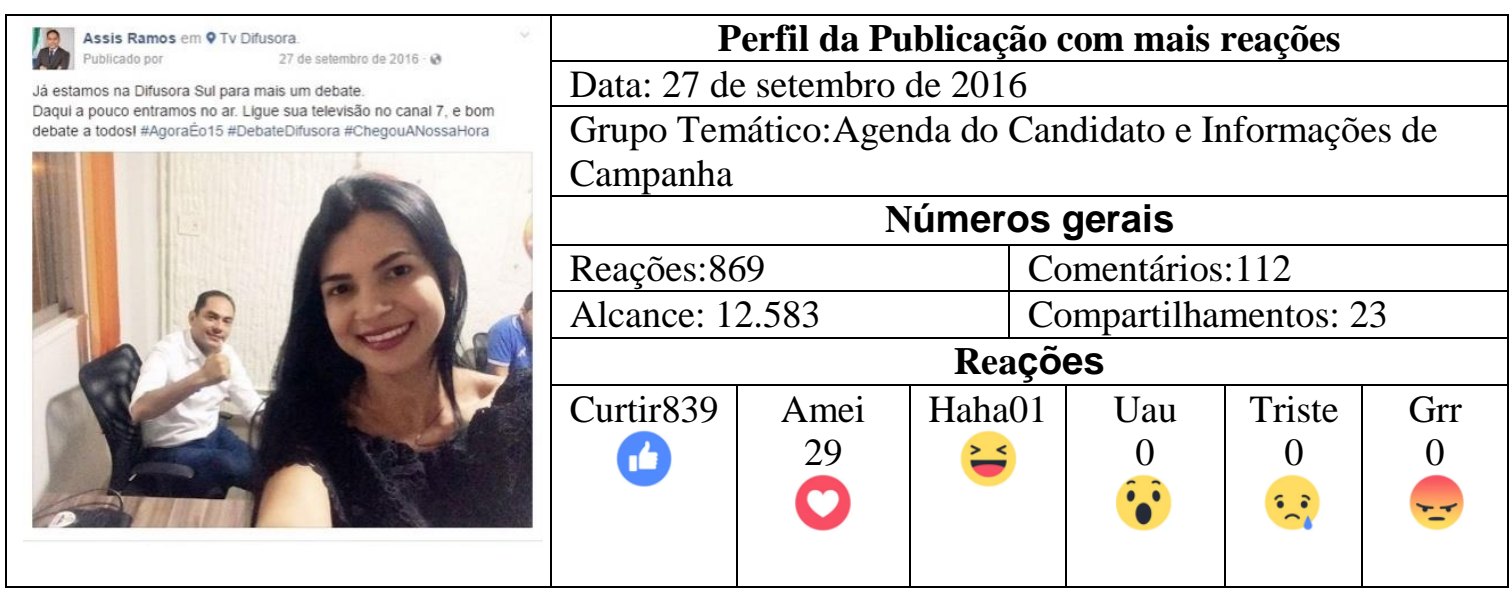

Fonte: Recorte da página do candidato no Facebook (2016) e Connau/UFMA/CNPq

O conteúdo se resumia a uma "foto-selfie", não produzida profissionalmente, de Assis Ramos, ao lado de sua esposa. A legenda, em tom descontraído, sugeria à audiência da página a realização de uma ação off-line: assistir ao debate. A estratégia de "ao vivo" foi observada em outras publicações, tornando-se um recurso exitoso para capturar a atenção do usuário.

A última publicação (Quadro 3) a ser analisada corresponde diretamente ao critério de propagabilidade. O compartilhamento é o recurso usado para espalhar informações no Facebook. As formas de compartilhamento público, para um amigo específico, para uma categoria de amigos e para um grupo criado dentro da própria rede, podem ser vistas com uma espécie de catalisador de conteúdo, dispersando a mensagem para além dos limites da audiência da própria página.

Quadro 3 - Descrição da publicação feita com “meme” publicado na página

\begin{tabular}{|c|c|c|c|c|c|c|}
\hline \multirow{8}{*}{ 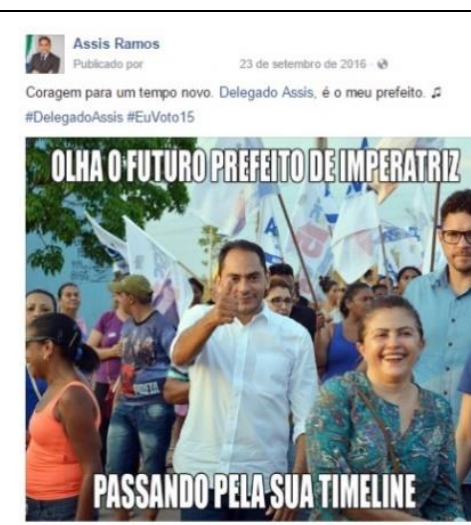 } & \multicolumn{6}{|c|}{ Perfil da Publicação com mais compartilhamento } \\
\hline & \multicolumn{6}{|c|}{ Data: 23 de setembro de 2016} \\
\hline & \multicolumn{6}{|c|}{ Grupo Temático:Uso de memes } \\
\hline & \multicolumn{6}{|c|}{ Números gerais } \\
\hline & \multicolumn{2}{|c|}{ Reações:791 } & & \multicolumn{3}{|c|}{ Comentários:602 } \\
\hline & \multicolumn{2}{|c|}{ Alcance: 96.279} & & \multicolumn{3}{|c|}{ Compartilhamentos: 23} \\
\hline & \multicolumn{6}{|c|}{ Reações } \\
\hline & Curtir742 & $\begin{array}{c}\text { Amei } \\
40 \\
0\end{array}$ & $\underset{2}{\text { Haha04 }}$ & $\begin{array}{c}\text { Uau } \\
0 \\
0^{\circ}\end{array}$ & $\begin{array}{c}\text { Triste } \\
05 \\
\therefore:\end{array}$ & $\begin{array}{c}\mathrm{Gr} \\
0 \\
=\end{array}$ \\
\hline
\end{tabular}

Fonte: Recorte da página do candidato no Facebook (2016) e Connau/UFMA/CNPq 


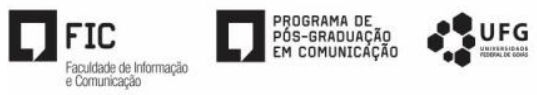

O "meme" usado nesta publicação obteve 602 compartilhamentos a partir do post original, alcançando mais de 96.000 contas do Facebook. Esta estratégia foi utilizada pontualmente, embora tenha sido assertiva, provocando os usuários disseminarem o conteúdo.

\section{CONSIDERAÇÕES FINAIS}

A partir de toda a discussão feita durante a análise desta pesquisa, notou-se que, por meio do mapeamento do conteúdo, divulgado durante o período da campanha eleitoral de Assis Ramos no Facebook, ficou evidente a preocupação da equipe de marketing em alavancar a imagem nas redes sociais. A quantidade expressiva de interações na página ao longo do período analisado, evidencia o crescimento da popularidade na web. Da estratégia, aos resultados, notou-se também que a busca por engajamento dos usuários na página gerou resultados, ampliando a propagabilidade de conteúdo, conforme indicado pelas variáveis apresentadas. A estratégia de comunicação na rede social, mais do que fazer com que a popularidade do candidato aumentasse, ajudou a guiar o planejamento de outras mídias. E mesmo sem poder dimensionar como isso foi decisivo para o resultado positivo da campanha, o que é apresentado mostra o quanto o posicionamento na rede torna-se estratégico para aproximação com o público.

\section{REFERÊNCIAS}

AGGIO, C.; MARQUES, F. P. J. A.; SAMPAIO, R. (Org.). Do clique à urna: internet, redes sociais e eleições no Brasil. Salvador: EDUFBA, 2012.

AGGIO, Camilo; REIS, Lucas. Campanha eleitoral no Facebook: usos, configurações e o papel atribuído a esse site por três candidatos eleitos nas eleições municipais de 2012. Revista Compolítica, Rio de Janeiro, n.3, v. 2, p. 156-188, jul./dez. 2013.

BACHINI, Natasha. Sob o piado do Twitter: o novo tom das campanhas eleitorais com a difusão da internet no Brasil - novos resultados. In: CONGRESSO LATINO AMERICANO DE CIÊNCIA POLÍTICA,6., 2012, Quito, Equador. Anais... Quito, Equador: Associação Latino Americana de Ciência Política (ALACIP), 2012.

BRASIL. Presidência da República. Secretaria de Comunicação Social. Pesquisa brasileira de mídia 2015: hábitos de consumo de mídia pela população brasileira. Brasília: Secom, 2014.

BRUGNAGO, Fabrício; CHAIA, Vera. A nova polarização política nas eleições de 2014: radicalização ideológica da direita no mundo contemporâneo do Facebook. Revista Aurora, São Paulo, v.7, n. 21, p. 99-129, out./jan. 2015. 
CARLOMAGNO, Márcio Cunha. Eleições como de costume? Uma análise longitudinal das mudanças provocadas nas campanhas eleitorais brasileiras pelos impactos das tecnologias digitais (1998 - 2914). In: CONGRESSO DA ASSOCIAÇÃO BRASILEIRA DE PESQUISADORES EM COMUNICAÇÃO E POLÍTICA, 6., 2015, Rio de Janeiro. Anais... Rio de Janeiro: Pontifícia Universidade Católica do Rio de Janeiro, 2015.

GOMES, W. et al. Participação Política Online: Questões e Hipóteses de Trabalho. In: MAIA, R. et al. Internet e Participação Política no Brasil. Porto Alegre: Sulina, 2011.

JAMIL, Francisco Paulo; SAMPAIO, Rafael. Internet e eleições 2010 no Brasil: rupturas e continuidadesnos padrões mediáticos das campanhas políticas online. Revista Galáxia, São Paulo, n. 22, p. 208-221, dez. 2011.

JENKINS, Henry. Cultura da convergência. São Paulo: Aleph, 2006.

JENKINS, Henry; FORD, Sam; GREEN, Joshua. Cultura da conexão: criando valor esignificado por meio da mídia propagável. São Paulo: Aleph, 2014.

MARQUES, F. P. J. A.; SAMPAIO, R. C. Election after election: rupturas e continuidades nos padrões midiáticos das campanhas políticas online. In: ENCONTRO ANUAL DA COMPÓS, 20., 2011. Porto Alegre. Anais... Brasília: Compós, 2011.

PARMELEE, J.; BICHARD, S. Politics and the Twitter Revolution: How Tweets Influence the Relationship between Political Leaders and the Public.United Kingdom: Lexington Books, 2012.

PENTEADO, Claudio Luis de Camargo. Marketing político na era digital: perspectivas e possibilidades. Revista USP, São Paulo, n. 90, p. 6-23, jun./ago. 2011.

RECUERO, Raquel. Redes Sociais na Internet, Difusão de Informação e Jornalismo: Elementos para discussão. In: SOSTER, Demétrio de Azeredo; FIRMINO, Fernando (Org.). Metamorfoses jornalísticas 2: a reconfiguração da forma. Santa Cruz do Sul: UNISC, 2009. p. 1-269.

SANTANA, Rosane Soares. Participação Política dos Eleitores de Salvador usuários de mídias sociais nas eleições de 2014. In: CONGRESSO DA ASSOCIAÇÃO BRASILEIRA DE PESQUISADORES EM COMUNICAÇÃO E POLÍTICA, 6., 2015, Rio de Janeiro. Anais... Rio de Janeiro: Pontifícia Universidade Católica do Rio de Janeiro, 2015

STROMER-GALLEY, Jennifer. On-Line interaction and why candidates Avoid it. Journal of Communication, v. 50, n. 4, p. 111-132, 2000.

TOWNER, Terri; DÚLIO, D. A. All Political Participation Is Socially Networked? New Media and the 2012 Elections. Social Science Computer Review, v. 31, n. 5, p. 527-541, 2013.

YIN, R. K. Estudo de caso: planejamento e métodos. 5. ed. Porto Alegre: Bookman, 2015. 